\title{
Prognostic Factors Associated with Mortality Related to Stroke in Bangui (Central African Republic)
}

\author{
Pascal Mbelesso*, Emmanuel Yangatimbi, Vincent de Paul Senekian \\ Department of Neurology, University Hospital Center of the Sino-Central African Friendship of Bangui, Bangui, \\ Central African Republic \\ Email: *pmbelesso@yahoo.com
}

How to cite this paper: Mbelesso, P., Yangatimbi, E. and de Paul Senekian, V. (2018) Prognostic Factors Associated with Mortality Related to Stroke in Bangui (Central African Republic). Neuroscience \& Medicine, 9, 198-208.

https://doi.org/10.4236/nm.2018.94020

Received: November 15, 2018

Accepted: December 24, 2018

Published: December 27, 2018

Copyright $\odot 2018$ by authors and Scientific Research Publishing Inc. This work is licensed under the Creative Commons Attribution International License (CC BY 4.0).

http://creativecommons.org/licenses/by/4.0/

\begin{abstract}
Stroke is a very common neurological condition that causes permanent disability in half of the cases, at least in sub-Saharan Africa. They represent the second most common cause of death in Africa. Objective of this study was to evaluate the prognostic value of the intake period of patients suffering from these conditions on the survival time of one month of hospitalization in hospitals in Bangui. We conducted a prospective study cross prognostic kind in the neurology departments, internal medicine and intensive care units of two large central hospitals from February to August 2017. Subject recruitment was complete with a made questionnaire based on the modified one of the World Health Organization on neurological disorders. A total of 154 patients were included, with a mean age of 63.15 years \pm 10.98 and extremes ranging from 38 to 91 years. A male predominance was noted (60\%) with a sex ratio $(\mathrm{M} / \mathrm{F})$ of 1.5 . For 76 subjects $(49.35 \%)$, care was taken with a hospital admission period of less than or equal to one day, while for 78 other 78 (50.65\%) the admission period was higher to one day. Average admission time patients caught early was 1.00 day and the upper limit intake to one day was $4.59 \pm 2.33$ days with a statistically significant difference $(\mathrm{p}<0.0001)$. Median admission delay for patients treated late was 4 days. Pre-hospital and hospital determinants by admission delay are presented in Table 1. The survival time was better in the group of patients who were treated early $(\mathrm{p}=$ 0.0039). This study shows the negative impact of late management on the survival time of patients.
\end{abstract}

\section{Keywords}

Stroke, Prognostic Factors, Mortality, Survival Time, Central African Republic 


\section{Introduction}

Stroke is a real public health issue. Every year, about fifteen million people suffer from it all over the world, of which five million die and another five million live with permanent disabilities [1]. In developing countries, they represent the second leading cause of death [2] and more than $80 \%$ of deaths caused by these conditions are of interest to these countries. The incidence of stroke in 2030 is estimated at 23 million, and the developing countries will bear $30 \%$ of that number [3] [4]. The decline in mortality rates observed in the industrialized countries is the result of better primary and secondary prevention and better management in the acute phase.

In sub-Saharan Africa, the average admission time varies from 24 hours to 365 days while in the West it is 30 minutes to 18 hours [5] [6]. The prognostic factors of hospitalized stroke are dominated by neurological factors (seizures, recurrent stroke), cardiac factors and decubitus complications. The overall mortality at one month ranges from $20.3 \%$ to $44.6 \%$ in sub-Saharan Africa compared with $22.9 \%$ in the West [7] [8] [9] [10]. In addition, care in a specialized setting within the first 48 hours reduces the mortality and disability rate by $20 \%$ [11].

In the Central African Republic, stroke accounted for $8.8 \%$ of hospitalized patients in the neurology unit in Bangui in 2004, with a one-month mortality rate of $33 \%$ [12]. The causes and factors associated with mortality from stroke in Central Africa are not yet known. The insufficiency of the means of neurological exploration, and source of diagnostic errors, hampers the efficient management of the patient's victims of these affections which results in an increase of the mortality. This high lethality would also be related to a longer admission period where patients admitted beyond 24 hours would be more at risk of death. The admission period for patients with stroke may be a pre-hospital prognostic factor associated with mortality, very few documented factor in Sub-Saharan Africa. That is why we conducted this study to evaluate the prognostic value of the intake period of patients suffering stroke on survival time in a month of hospitalization in Bangui hospitals.

Table 1. General characteristics of patients according to the admission deadline.

\begin{tabular}{|c|c|c|c|c|c|c|c|}
\hline & \multicolumn{2}{|c|}{$\begin{array}{l}\text { Admission } \\
\text { deadline } \\
\leq 1 \text { day }\end{array}$} & \multicolumn{2}{|c|}{$\begin{array}{l}\text { Admission } \\
\text { deadline } \\
>1 \text { day }\end{array}$} & \multicolumn{2}{|c|}{ Total } & \multirow[t]{2}{*}{$\mathrm{P}$} \\
\hline & $\mathrm{N}$ & $(\%)$ & $\mathrm{N}$ & $(\%)$ & $\mathrm{N}$ & $(\%)$ & \\
\hline \multicolumn{8}{|c|}{ Sex } \\
\hline Male & 48 & 63.16 & 44 & 56.41 & 92 & 59.74 & \multirow{2}{*}{0.3933} \\
\hline Female & 28 & 36.84 & 34 & 43.59 & 62 & 40.26 & \\
\hline \multicolumn{8}{|l|}{ Initial management } \\
\hline Health workers & 71 & 93.42 & 34 & 44.16 & 105 & 68.63 & \multirow[t]{2}{*}{0.0001} \\
\hline Traditional healers & 5 & 6.58 & 43 & 55.84 & 48 & 31.37 & \\
\hline
\end{tabular}




\section{Continued}

Health worker category

Neurologist/Cardiologist

General practitioner

Male/female nurse

Pre-hospital determinants

Arterial hypertension

Diabetes

Epilepsy

Heart disease

Hypercholesterolemia

\section{Hospital determinant}

Swallowing disorders

Convulsions

Inhalation Pneumopathy

Thrombophlebitis

Bedsores

Rank in scale

Death

$\begin{array}{rrrrrr}20 & 27.40 & 0 & 0.00 & 20 & 18.18 \\ 45 & 61.64 & 23 & 62.16 & 68 & 61.82 \\ 8 & 10.96 & 14 & 37.84 & 22 & 20.00\end{array}$

0.0001

0.0089

0.0333

0.7360

$\begin{array}{lllllll}\text { No } & 59 & 77.63 & 55 & 70.51 & 114 & 74.03\end{array}$

$\begin{array}{lllllll}\text { Yes } & 3 & 3.95 & 2 & 2.56 & 5 & 3.25\end{array}$

$\begin{array}{lllllll}\text { No } & 73 & 96.05 & 72 & 92.31 & 145 & 94.16\end{array}$

0.6711

$\begin{array}{lllllll}\text { Yes } & 10 & 13.16 & 3 & 3.85 & 5 & 3.25\end{array}$

0.1538

$\begin{array}{lllllll}\text { No } & 15 & 19.74 & 13 & 16.67 & 28 & 18.18\end{array}$

$\begin{array}{lllllll}\text { Yes } & 11 & 14.47 & 3 & 3.90 & 14 & 9.15\end{array}$

0.6014

$\begin{array}{lllllll}\text { No } & 7 & 9.21 & 1 & 1.30 & 8 & 5.23\end{array}$

0.0379

$\begin{array}{lllllll}\text { No } & 65 & 85.53 & 56 & 71.79 & 121 & 78.57\end{array}$

$\begin{array}{lllllll}\text { Yes } & 10 & 13.16 & 8 & 10.26 & 18 & 11.69\end{array}$

0.5753

$\begin{array}{lllllll}\text { No } & 66 & 86.84 & 70 & 89.74 & 136 & 88.31\end{array}$

$\begin{array}{lllllll}\text { Yes } & 11 & 14.47 & 21 & 26.92 & 32 & 20.78\end{array}$

$\begin{array}{lllllll}\text { No } & 65 & 85.53 & 57 & 73.08 & 122 & 79.22\end{array}$

0.0569

$\begin{array}{lllllll}\text { Yes } & 2 & 2.63 & 11 & 14.10 & 13 & 8.44\end{array}$

0.0105

$\begin{array}{lllllll}\text { No } & 74 & 97.37 & 67 & 85.90 & 141 & 91.56\end{array}$

$\begin{array}{lllllll}\text { Yes } & 0 & 0.00 & 1 & 1.28 & 1 & 0.65\end{array}$

$\begin{array}{lllllll}\text { No } & 46 & 100 & 77 & 98.72 & 153 & 99.35\end{array}$

$\begin{array}{lllllll}\text { Yes } & 2 & 2.63 & 18 & 23.08 & 20 & 12.99\end{array}$

$\begin{array}{lllllll}\text { No } & 74 & 97.37 & 60 & 76.92 & 134 & 87.01\end{array}$

0.0002

0.3220

0.0352

$\begin{array}{lllllll}>3 & 29 & 78.33 & 31 & 68.89 & 60 & 57.14\end{array}$

$\begin{array}{lllllll}\text { Yes } & 15 & 19.74 & 31 & 39.74 & 46 & 29.87\end{array}$

$\begin{array}{lllllll}\text { No } & 61 & 80.26 & 47 & 60.26 & 108 & 70.13\end{array}$

0.0067 


\section{Methodology}

This is a prospective cross-sectional prognostic study carried out in Bangui in the neurology departments of the Sino-Central African University Hospital Center, internal medicine departments of the Community University Hospital Center, and the intensive care units of these hospitals, from February to August 2017. Recruitment of the subjects was exhaustive using a questionnaire based on the modified questionnaire of the World Health Organization (WHO) on neurological disorders [13]. This questionnaire included several items that are:

- Information on the survey: admission date, period of admission, residence, telephone contacts of the patient or accompanying, place of hospitalization;

- Sociodemographic data: age, sex, level of education, marital status, occupation;

- Patient history: medical history including history of previous stroke, history of high blood pressure, diabetes, high cholesterol, smoking, alcoholism, embolism heart disease, obesity, oral contraceptives. It should be noted that the precise date of installation of the disorders, the mode of installation, the delay in taking charge, the quality of the health worker who carried out the first treatment, the treatments administered and in progress were also specified;

- Clinical data: general signs (body temperature, blood pressure, weight, height, WHO performance index), type of deficit and its location, other abnormalities of the physical examination;

- Results of the para clinical examinations: possibly brain scan, electrocardiogram, echocardiography, biological examinations (blood sugar, triglyceridemia, total cholesterolemia, HDL/LDH cholesterol, serum creatinine;

- Evolution: date and output mode (output improved, deaths and causes of death), complications (aspiration pneumonia, pulmonary embolism, deep vein thrombosis, pressure sores, septicemia);

- The one-month post-hospital follow-up on the clinical data and the Rankin score.

Were included all patients over the age of eighteen years and meets the clinical definition of our study: lack of brain function (motor, sensory, visual, phasic) or a cranial nerve, focal, without brutal concept trauma, spontaneous and persistent in time, for more than twenty-four hours [11]; reviewed at one-month follow-up; whose informed consent has been obtained from the patient if he is aware of it or from a third party informing the subject. The survivors were seen on the day of hospital discharge and one month of diagnosis.

Is not part of our sample, any patient not seen at one month, except those who died during hospitalization.

Data processing and analysis was done with Statview 5.0 software (SAS Institue, Cary, USA). Two analyzes were made:

- Univariate analysis where the means of the quantitative variables (age, time of admission, survival time) were compared by the Chi square test or the Ficher test; 
- Simplified multivariate analysis using the step-by-step method to arrive at the final model.

The follow-up curves were performed according to the Kaplan-Meier method and compared with each other using Log-Rank tests.

\section{Result}

A total of 154 patients' victims of stroke were included. The average age of patients was $63.15 \pm 10.98$ years with extremes of 38 and 91 years. The median age was 63 years old. Ninety-two subjects (60\%) were male and $62(40 \%)$ female, a sex ratio $(\mathrm{M} / \mathrm{F})$ of 1.5 . For 76 subjects $(49.35 \%)$, care was taken with a hospital admission period of less than or equal to one day and for the remaining 78 (50.65\%) the admission period was longer than one day. The average admission time patients caught early was 1.00 day and the upper limit intake to one day was $4.59 \pm 2.33$ days with a statistically significant difference $(\mathrm{p}<0.0001)$. The median admission delay for patients treated late was 4 days. Of a total of 153 patients consulted before hospitalization (one patient had missing data and has not been included in this total), 105 patients (68.63\%) were treated at the beginning of their illness by a health worker and 48 others $(31.37 \%$ ) by a traditional healer before the hospitalization. Among the 105 patients treated by a health worker, 68 patients $(61.82 \%)$ were examined by a general practitioner.The pre-hospital and hospital determinants based on the admission period are presented in Table 1. The survival time was better in the group of patients who were managed early $(\mathrm{p}=0.0039)$. Of the 46 cases $(29.87 \%)$ of deaths observed in our study, 31 cases $(39.74 \%)$ were treated late versus 15 cases $(19.74 \%)$ in the other group $(\mathrm{p}=0.0067)$. The mean survival time was 25 days \pm 11 in the group of patients treated during the day and 21 days \pm 12 in the group of patients treated after one day. The median survival in both groups was 30 days.

\section{Discussion}

\subsection{Limitations of the Study}

The absence of brain imaging that can confirm or eliminate the clinical diagnosis and specify the type of stroke is the most important limitation of this work, so that patients have certainly had to avoid recruitment that was intended to be exhaustive. In addition, the duration of the follow-up of the patients and the duration of the study were probably not long enough, although the number of patients was calculated and that the difference on the time of admission is significant. A follow-up over a period of one year would have allowed us a consistent evaluation of functional disability over time. Nevertheless, our study was a prognostic study in the form of a prospective cohort survey. The cases of stroke have been identified and included according to the WHO definition taking into account the five clinical signs whose association surrounds sensitivity close to $80 \%$. All patients were recruited by a neurologist, which limits the selection bias that would be due to misdiagnosis in a context of absence of brain im- 
aging. The study was prospective kind, facilitating the registration of the maximum expected information.

\subsection{Age and Sex}

This study shows that the average age of stroke patients was 63.15 years with extremes of 38 and 91 years. These data overlap with those described, both in Africa [10] [14] [15] and in the West [16] and Middle East [17]. This great age confirms the influence of this variable as a risk factor for stroke and corroborates the data of literature [18]. Note that Pellerin et al. reported that the risk of stroke increases proportionally with age, and that after age 55 , the risk is doubled after each decade [19].

Regarding sex, we found that men were the most represented in our sample without a statistically significant difference. This finding is consistent with descriptions by some authors in Congo (62.70 years) in Central Africa [14], Dakar (61.3 years) and Mauritania (58 years) in West Africa [15] as in the West [16], apart from Touré et al. who have regained a female predominance [10]. For this variable, it is merely a finding which has no scientific explanation.

\subsection{Admission Deadline}

During our work, the average time to hospital for stroke patients was $4.59 \pm 2.33$ days. This period is significantly higher than that reported in Brazzaville $(28.20 \mathrm{~h})$ in the sub-region [14] as well as that observed in the developed countries in the West [5] [16] and in the USA [20] where there is a better organization of care structures. This lengthening of the admission period can also be explained by the mentality of our community, which seeks first to link phenomena of sudden onset to a supernatural cause. This can testify to the ignorance of the population regarding this affection. This calls into question the need to carry out awareness-raising activities in order to enlighten the population with a view to reducing the harmful consequences that may result.

\subsection{Level of Study}

We found that $58.4 \%$ of the population in our study had a low level of education that was statistically significantly associated with survival. This has a negative impact on early care. These results are similar to those of Siddiqui et al. [17]. This phenomenon also explains the magical-mystical considerations are blocking and lengthen the period of admission.

\subsection{Pre-Hospital Care}

The pre-hospital care of our patients was done in 68.63\% (105 patients) by health workers against $31.37 \%$ (48 patients) by traditional healers. General practitioners were the category most represented health workers. The patients were followed in the two main central hospitals of the city of Bangui: the Sino-Central African University Hospital Center, which has the only neurology 
service, and the Community University Hospital Center where an internal medicine service is located. Of the 154 patients admitted to our study, 29 (38.16\%) were hospitalized and managed at the Community University Hospital Center and 47 (61.84\%) were treated at the Sino-Central African University Hospital Center from Bangui;there was no statistically significant difference in care between the two hospitals $(\mathrm{p}=0.3152)$.

On the other hand, 76 subjects (49.35\%) were treated with an admission period of less than or equal to one day and 78 subjects (50.65\%) with an admission period of more than one day $(\mathrm{p}<0.0001)$. This phenomenon is due to the retention of patients for a very long time outside adequate care structures and confirms what Maiga et al. reported that $90.6 \%$ of caregivers hospitalized patients in their own structures, and only $9.4 \%$ routinely referred patients to a higher level of the health pyramid [21]. Regarding therapeutic route of the patients, we noted that $45.6 \%$ of them had claimed to come from traditional healers, and $45.4 \%$ reported coming from peripheral structures or directly from their homes. This is a significant lack of knowledge of people about stroke as it was already mentioned in a study in South Africa [22]. Thus, the lack of systematic referencing of patients in a specialized service (neurology department) and the use of traditional first-line medicine delay the management of these, and are factors that can promote an increase in the mortality rate linked to this disease.

\subsection{Pre-Hospitalized Determinants}

A number of factors have been identified as potentially pre-hospital determinants associated with stroke mortality. These are high blood pressure and a history of stroke. Note that our finding corroborates the literature data, especially regarding hypertension where the relative risk is 4 for cerebral infarction [11], while Maïga et al. reported that $61.1 \%$ of Malian prescribers cited it as a risk factor [21]. Similarly, some authors [7] [8] [23] stressed its importance is as the predominant risk factor, whether as main causes of stroke. In our sample during the logistic regression analysis, hypertension was not statistically significantly associated with survival, this could be explained by good management of severe hypertension in stroke patients during hospitalization and that hypertension would not cause mortality.

Regarding the history of stroke in our study, it was also associated with statistically significant for the survival of our patients. In the literature, this phenomenon has been mentioned as well as other pathologies [11] [24]. Too bad it does not yet exist in the Central a social healthcare system.

\subsection{Hospital Determinants}

Swallowing disorders, sepsis and bedsores were seen as determinants hospitalized in our sample with a statistically significant difference and a tendency for aspiration pneumonia. The swallowing disorders with their corollaries of pulmonary infections were observed in $42.68 \%$ of cases. Figure 1 and Figure 2 
are comparable to those reported elsewhere in the literature [25] [26] [27]. Even with adequate management structures, it is not immune to this disorder with its complications which Smithard et al. have found a significant association in a study assessing the risk of pulmonary infections in patients with Parkinson's disease swallowing during the first week after cerebral infarction [28]. Moreover, for Hilker et al., inhalation pneumonia increased the mortality rate by three [29], while Vander Worp and Kappelle alleged that they caused a quarter of deaths in the first month after stroke in another series [30]. Thus, swallowing disorders may have a negative prognostic value on the survival time of patients with stroke.

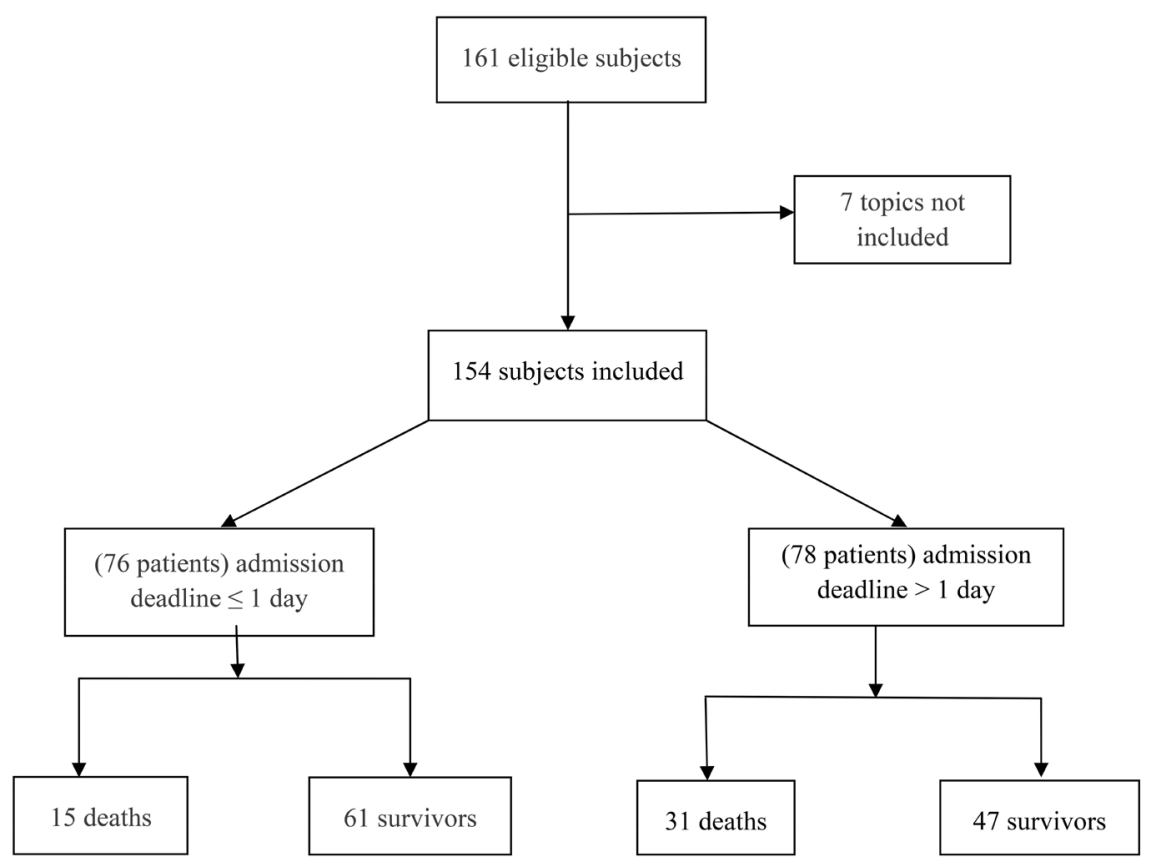

Figure 1. Flow diagram of the selection of the study population.

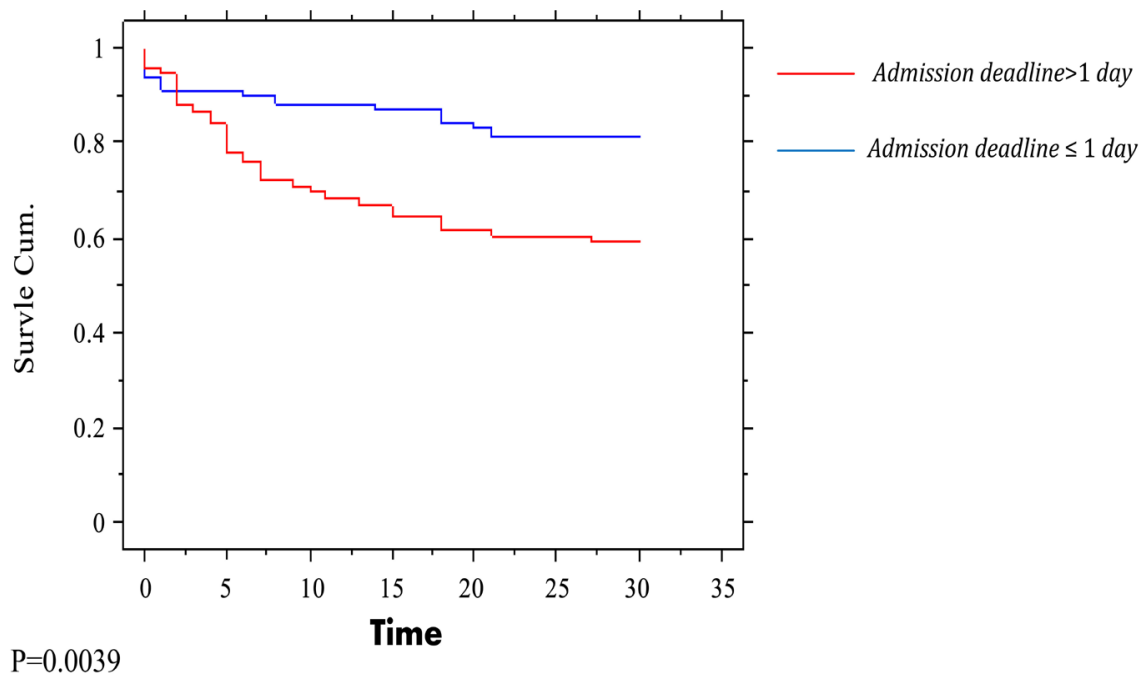

Figure 2. Survival curve based on the admission deadline. 


\subsection{Functional Disability Assessed at One Month}

The functional impairment evaluated at one month by the Rankin scale [31] amended in the series note was more severe both in patients treated early (29 patients or $78.33 \%$ ), than among those who were taken into load beyond one day (31 patients or 68.89\%). This finding is similar to what was reported in Parakou in Benin [32]. Note that at Dakar, Senegal, in a monthly tracking study over twelve months with the Barthel's Index [33], the authors had more than half of the patients (58.3\%) become self-sufficient [34]. Barthel's index was used to assess functional abilities, while Rankin assessed disability after a stroke. Nevertheless, the lack of human and material resources in the field of functional rehabilitation in Central African Republic in general and the two central hospitals in Bangui in particular, explain in part the difficulties regarding the best care, which translates into the importance of the functional disability of our patients.

\subsection{Survival}

In our study 46 cases (29.9\%) deaths were observed. This rate is higher than that reported (20\%) in France [19] and in some Western countries [35], as well as in Canada [36]. This reflects the severity of the disease and confirms the importance of setting up a neurovacular unit to reduce morbidity and mortality in this condition. Also, the survival time was better in the group of patients managed early $(p=0.0039)$.

\section{Conflicts of Interest}

The authors declare no conflicts of interest regarding the publication of this paper.

\section{References}

[1] Lewis, I. (2004) Chapter 16: Deaths from Stroke. In: The Atlas of Heart Disease and stroke, WHO, Geneva, 52-54.

[2] Lopez, A.D., Mathers, C.D., Ezzati, M., Jamisson, D.T. and Murray, C.J. (2006) Global and Regional Burden of Disease and Risk Factors, 2011: Systematic Analysis of Population Health Data. The Lancet, 367, 1747-1757. https://doi.org/10.1016/S0140-6736(06)68770-9

[3] OMS (Organisation Mondiale de la Santé) (2013) Maladies cardio-vasculaires. Centre des médias Aide-mémoire Mars 2013. http://www.who.int/mediacentre/factsheets/fs317/fr/

[4] Strong, K., Mathers, C. and Bonita, R. (2007) Preventing Stroke: Saving Lives around the World. The Lancet Neurology, 6, 182-187. https://doi.org/10.1016/S1474-4422(07)70031-5

[5] Woimant, D.N.F. (2008) Il faut hospitaliser les accidents vasculaires cérébraux en unité neurovasculaire. Consensus Cardio pour le praticien, 39, 7-8.

[6] Mathieu-Blondet, A., Malet, A., Devy, R., Causeret, M., Rouquette, A. and Fanello, S. (2008) Evaluation de la prise des patients atteints d'accident vasculaire cérébral (AVC) dans un centre hospitalier. Santé Publique, 6, 561-574. https://doi.org/10.3917/spub.086.0561 
[7] Diagana, M., Traoré, H., Bassima, A., Druet-Cabana, C.M., Preux, P.M. and Dumas, M. (2002) Apport de la tomodensitométrie dans le diagnostic des accidents vasculaires cérébraux à Nouakchott, Mauritanie. Médecine Tropicale, 62, 145-149.

[8] Zenebe, G., Alemayehu, M. and Asmera, J. (2005) Characteristics and Out-Comes of Stroke at Tikur Anbessa Teaching Hospital, Ethiopia. Ethiopian Medical Journal, 43, 251-259.

[9] Feigin, V.L., Lawes, C.M., Bennett, D.A. and Anderson, C.S. (2003) Stroke Epidemiology: A Review of Population-Based Studies of Incidence, Prevalence, and Case-Fatality in the Late 20th Century. The Lancet Neurology, 2, 43-53. https://doi.org/10.1016/S1474-4422(03)00266-7

[10] Touré, K., Diagne, S.N., Seck, L.B., Sow, A.D., Ndiaye, M., Diop, M.S., Gueye, L., Diop, A.G. and Ndiaye, M.M. (2010) Facteurs prédictifs de mortalité par accident vasculaire cérébral à la clinique neurologique du CHU de Fann, Dakar-Sénégal. AJNS, 29, 29-36.

[11] Bejot, Y., Chantegret, A., Ben Salem, D., Osseby, G.-V., Girond, M. and Freysz, M. (2010) Prise en charge des accidents vasculaires cérébraux en urgence. EMC-Médecine d urgenc, 5, 1-21. https://doi.org/10.1016/S1959-5182(10)38147-5

[12] Mbelesso, P., Tabo, A., Seboulo, P.C., Yangatimbi, A., Kette, C.G. and Senekian, V.P. (2007) Aspects épidémiologiques des accidents vasculaires cérébraux à l'hôpital de l'Amitié à Bangui en République Centrafricaine. Le Bénin Médical, 37, 44-46.

[13] Organisation mondiale de la santé (1989) Task Force on Stroke and Other Cerebrovascular Disorders. Recommandations on Stroke Prevention, Diagnosis and Therapy. Stroke, 20, 1407-1431.

[14] Gombet, T., Ossou-Nguiet, P.M., Ampion, M.O., Ellenga-Mbolla, B.F, BandzouziNdamba, B., Matali, E. and Okemba-Ibarra, A. (2012) Facteurs de mortalité des accidents vasculaires cérébraux au CHU de Brazzaville. Résumé Jnlf, Nice.

[15] Diagana, M., OuldAbdallahi Salem, B., N'diaye, M., Le Cornet, C., Quet, F., OuldSidi Aly, A., Ould Abdel Hamid, I. and Preux, P.M. (2008) Impact des filières de soins en phase aiguë dans l'amélioration fonctionnelle des AVC à Nouakchott. AJNS, 27, 38-46.

[16] Sekoranja, L., Griesser, A.C., Wagner, G., Njamnshi, A.K., Temperli, P., Herrmann, F.R., Grandjean, R., Niquille, M., Vermeulen, B., Rutschmann, O.T., Sarasin, F. and Sztajzel, R. (2009) Factors Influencing Emergency Delays in Acute Stroke Management. Swiss Medical Weekly, 139, 393-399.

[17] Siddiqui, M., Siddiqui, S.R., Zafar, A. and Khan, F.S. (2008) Factors Delaying Hospital Arrival of Patients with Acute Stroke. JPMA, 58, 178-181.

[18] Balogou, A.A.K., Grunitzky, E.K., Assogba, K., Apetse, K., Kombate, D. and Amouzouvi, D. (2008) Accidents vasculaires cérébraux chez le sujet jeune (15 à 45 ans) dans le service de neurologie du CHU Campus de Lomé. AJNS, 27, 44-51.

[19] Pellerin, C., Mauget, Y., Bouju, A., Rouanet, F., Petitjean, M.E. and Dabadie, P. (2003) Accident vasculaire cérébral. Médecine d urgence, 107-117.

[20] Lacy, C.L., Mba, D.C.S., Bueno, M. and Kostis, J.B. (2001) Delay in Presentation and Evaluation for Acute Stroke: Stroke Time Registre for Outcomes Knowledge and Epidemiology. Stroke, 32, 63-69. https://doi.org/10.1161/01.STR.32.1.63

[21] Maïga, Y., Albakaye, M., Diango, D., Kanikomo, D., Seybou, H., Minta, I., Diakité, S., Traoré, H.A. and Guillon, B. (2013) Modalités de prise en charge des accidents vasculaires cérébraux au Mali (Afrique de l'ouest): Une enquête de pratiques. Mali Médical, 28, 30-35.

[22] Wasserman, S., De Villers, L. and Bryer, A. (2009) Community-Based Care of 
Stroke Patients in a Rural African Setting. South African Medical, 99, 579-583.

[23] Raveloson, N.E., Zodaly, N., Rakotoarivony, S.T., Mbolamena, R.L. and Randriamiarana, J.M. (2011) Aspects épidémiocliniques, évolution et tomodensitométriques des accidents vasculaires cérébraux hémorragiques (34 cas). Revue d Anesthésie-Réanimation et de Médecine d Urgence, 3, 15-19.

[24] Goldstein, L.B., Bushnell, C.D., Adams, R.J., Appel, L.J., Braun, L.T., Chaturvedi, S., Creager, M.A., Culebras, A., Eckel, R.H., Hart, R.G., Hinchey, J.A., Howard, V.J., Jauch, E.C., Levine, S.R., Meschia, J.F., Moore, W.S., Nixon, J.V.I. and Pearson, T.A. (2011) American Heart Association Stroke Council on Cardiovascular Nursing, Council on Epidemiology and Prevention, Council Fort High Blood Pressure Research, Council on Peripheral Vascular Disease, and Interdisciplinary Council on Quality of Care and Outcomes Research. Guidelines for the Primary Prevention of Stroke a Guideline for Healthcare Professionals from the American Heart Association/American Stroke Association. Stroke, 42, 517-84.

[25] Finestone, H.M. (2000) Safe Feeding Methods in Stroke Patients. The Lancet, 355, 1662-1663. https://doi.org/10.1016/S0140-6736(00)02234-0

[26] Gordon, C., Hewer, R.L. and Wade, D.T. (1987) Dysphagia in Acute Stroke. BMJ, 295, 411-414. https://doi.org/10.1136/bmj.295.6595.411

[27] Mann, G., Hankey, G.J. and Cameron, D. (2000) Swallowing Disorders Following Acute Stroke: Prevalence and Diagnostic Accuracy. Cerebrovascular Diseases, 10, 380-386. https://doi.org/10.1159/000016094

[28] Smithard, D.G., O’Neill, P.A., Park, C. and Morris, J. (1996) Complications and Outcome after Stroke: Does Dysphagia Matter? Stroke, 27, 1200-1204.

https://doi.org/10.1161/01.STR.27.7.1200

[29] Hilker, R., Poetter, C., Findeisen, N., Sobesky, J., Jacobs, A. and NevelingMeiss, D. (2003) Nosocomial Pneumonia after Acute Stroke: Implications for Neurological Intersive Care Medicine. Stroke, 34, 975-981. https://doi.org/10.1161/01.STR.0000063373.70993.CD

[30] Vander Worp, H.B. and Kappelle, L.J. (1998) Complications of Acute Ischaemic Stroke. Cerebrovascular Diseases, 8, 124-132. https://doi.org/10.1159/000015830

[31] Bonita, R. and Beaglehole, R. (1988) Modification of Rankin Scale: Recovery of Motor Function after Stroke. Stroke, 19, 1497-1500. https://doi.org/10.1161/01.STR.19.12.1497

[32] Adoukonou, T., Kouna-Ndouongo, P., Codjia, J.M., Covi, R., Tognon-Tchegnonsi, F., Preux, P.M. and Houinato, D. (2013) Coût direct hospitalier des accidents vasculaires cérébraux à Parakou au nord du Bénin. Pan African Medical Journal, 16, 121. http://www.ncbi.nlm.nih.gov/pmc/articles/PMC4021979/

[33] Mahoney, F.I. and Barthel, D.W. (1965) Functional Evaluation; the Barthel Index. Maryland State Medical Journal, 14, 61-65.

[34] SèneDiouf, F., Basse, A.M., Ndao, A.K., Touré, K., Thiam, A., Ndiaye, M.M., Diop, A.G. and Ndiaye, I.P. (2006) Pronostic fonctionnel des accidents vasculaires cérébraux dans les pays en voie de développement: Sénégal. ANNRMP, 46, 100-104.

[35] Sagui, E. (2007) Les accidents vasculaires cérébraux en Afrique Subsaharienne. Médecine Tropicale, 67, 596-560.

[36] Kapral, M.K., Hall, R., Stamplecoski, M., Meyer, S., Asllani, E., Fang, J., Richards, J., O'Callaghan, C. and Silver, F.L. (2011) Registry of the Canadian Stroke Network-Report on the 2008/09 Ontario Stoke (Ont) Audit. Institute for Clinical Evaluative Sciences, Toronto, 1-72. 